\title{
Pharyngeal Airway Changes Following Extraction versus Non- extraction Treatments of Class II Division 1 Growing Patients
}

\author{
Pariyakorn Sukniyom $^{1}$ and Smorntree Viteporn ${ }^{2 *}$ \\ ${ }^{1}$ Post Graduate Student, Faculty of Dentistry, Department of Orthodontics, Chulalongkorn University, Thailand \\ ${ }^{2}$ Professor, Faculty of Dentistry, Department of Orthodontics, Chulalongkorn University, Thailand
}

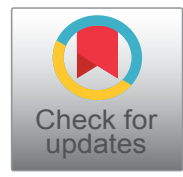

*Corresponding author: Smorntree Viteporn, Professor, Faculty of Dentistry, Department of Orthodontics, Chulalongkorn University, No.34, Henri Dunant Road, Pathum Wan, Bangkok 10300, Thailand, Tel: +66-819048486

\begin{abstract}
Background: There are several treatment modalities for Class II division 1 malocclusion, but there are only few studies exploring the treatment effect upon pharyngeal airway. The study aimed to compare the effects of extraction versus non-extraction mechanics on pharyngeal airway after treatment of Class II division 1 malocclusion.

Methods: The 60 Class II division 1 growing patients (whose mean age was $11.81 \pm 0.79$ years) were divided into Group I four first premolar extraction and Group II non-extraction with Class II traction. Skeletal development was evaluated from cervical vertebral maturation stages. Dento-skeleton and pharyngeal airway dimension were analyzed from consecutive lateral cephalograms before and after treatments. Significant differences within and between groups of the studied variables were evaluated by Paired-samples $T$ test and Independent-Samples T test $(p<0.05)$, respectively.
\end{abstract}

Results: Before treatment, the extraction group exhibited lower skeletal maturation, less retrognathic mandible, more protrusive incisors, wider oropharyngeal and hypopharyngeal airway, shorter soft palate and more anterior position of the tongue. Both treatments produced significant backward rotation of the mandible and retroclination of the upper incisors, downward and forward movement of hyoid bone. Significant increase of the nasopharyngeal and hypopharyngeal dimensions, soft palate length and thickness, tongue length and forward movement of the tongue were only found in the non-extraction group. Forward movement of the bony chin had significant correlations $(p<0.05)$ with the increase of hypopharyngeal dimensions, forward movement of the tongue and hyoid bone.

Conclusions: Treatment of Class II division 1 malocclusion in growing patients by either extraction or non-extraction mechanics did not produce significant adverse effect on pharyngeal airway dimension. Non-extraction treatment with Class II traction tended to have a positive effect on the pharyngeal airway.

\section{Keywords}

Class II division 1 malocclusion, Pharyngeal airway, Extraction, Class II traction

\section{Introduction}

Although esthetics, function and stability are the objectives of orthodontic treatment. Most treatments always focus on esthetics, stability and masticatory function. Respiratory function should be involved in orthodontic diagnosis and treatment planning as it may affect stability of the treatment results. Previous studies $[1,2]$ indicated that having normal airway is an important factor for normal growth and development of the craniofacial structures. Narrow pharyngeal airway is a predisposing factor for mouth breathing and obstructive sleep apnea (OSA) [3]. The oropharyngeal and hypopharyngeal airway was reduced in area by an average of $25 \%$ in OSA patients [4].

There is a significant relationship between pharyngeal airway space and growth pattern of the mandible. The antero-posterior diameter of the pharyngeal airway space at the level of soft palate and base of the tongue was the largest in the mandibular prognathism group, followed by normal mandible group and mandibular retrognathism group [5]. Some studies [6-8] concluded that Class II subjects had smaller dimension of pharyn-

Citation: Sukniyom P, Viteporn S (2019) Pharyngeal Airway Changes Following Extraction versus Non-extraction Treatments of Class II Division 1 Growing Patients. Int J Oral Dent Health 5:094. doi. org/10.23937/2469-5734/1510094

Accepted: July 10, 2019: Published: July 12, 2019

Copyright: (C) 2019 Sukniyom P, et al. This is an open-access article distributed under the terms of the Creative Commons Attribution License, which permits unrestricted use, distribution, and reproduction in any medium, provided the original author and source are credited. 
geal airway than those of Class I subjects.

The treatment modalities for Class II division 1 malocclusion are depended on facial growth, severity of the deformity and patient cooperation: Orthopedic appliances either headgear or functional appliance have been prescribed to growing patients $[9,10]$; orthodontic camouflage treatment with or without extraction has been prescribed to patients with mild to moderate skeletal discrepancies; and orthognathic surgery has been prescribed to adult patients with severe skeletal discrepancies [11]. The treatment effects on dento-skeleton and soft tissue profile have been thoroughly evaluated $[12,13]$ but there are only few studies exploring the treatment effect upon pharyngeal airway. Zheng, et al. [14] studied the effects of headgear with and without class II traction on the pharyngeal airway. Aksu, et al. [15] compared the treatment effects between cervical headgear and activator on the pharyngeal airway.

This study was undertaken upon the hypothesis that different treatment modalities for Class II division 1 malocclusion should have different effects on pharyngeal airway dimension. The study aimed to evaluate the alterations of pharyngeal airway and related structures following treatment of Class II division 1 malocclusion with and without extraction of four bicuspids. The knowledge achieved from the study should encourage clinicians to pay more attention to pharyngeal airway dimension when orthodontic treatment is prescribed to a growing patient.

\section{Materials and Methods}

The study was performed after the approval of the Ethics Committee, Faculty of Dentistry, Chulalongkorn University. The subjects comprised of 60 patients (28 boys and 32 girls) aged $11-14$ years (mean age 11.81 \pm 0.79 years) were selected regarding the inclusion criteria:

1. Complete permanent dentition with Class II Division 1 malocclusion and excessive overjet ( $\geq 5 \mathrm{~mm}$ ).

2. No history of facial trauma that could affect facial growth and development.

3. No respiratory problems such as pharyngeal pathology, nasal obstruction, chronic mouth breathing, snoring, obstructive sleep apnea, adenoidectomy or tonsillectomy.

4. Absence of craniofacial syndromes, obvious facial asymmetry, extreme vertical facial disproportion.

5. Available complete orthodontic records comprised patient history, age, sex, type of treatment, and standardized lateral cephalograms before (T1) and after treatments (T2). All lateral cephalograms were taken from the standardized orthophos (SIRONA) with the distance of 5 feet from object to film. The films were exposed with $64 \mathrm{KVp}, 8 \mathrm{~mA}$ and 9 seconds of exposure time. The subject's heads were stabilized in a cephalostat and the Frankfurt horizontal plane was parallel to the floor. Before taking the x-ray, each subject was asked to swallow hard, and then relax with teeth in centric occlusion and lips at repose.

All subjects were treated by the second author. The selected treatment protocol was considered from severity of incisor protrusion, space deficiency and facial profile.

\section{Treatment protocols}

Group I (extraction group): The sample was consisted of 30 patients ( 13 boys, 17 girls) whose mean age was $11.87 \pm 0.89$ years at beginning of treatment and 13.68 \pm 1.02 years at the end of treatment. The average treatment time was $1.81 \pm 0.70$ years. Cephalometric analysis indicated severe upper incisal protrusion causing upper lip protrusion and convex facial profile. Modern edgewise segmented arch technique with extraction of the four first premolars was prescribed to each patient. Maximum anchorage was prepared for the upper arch by utilization of a transpalatal arch and moderate anchorage for the lower arch. Individual canine retraction with $\mathrm{T}$ loop type $\mathrm{B}$ was prescribed for canine retraction.

Group II (non-extraction group): The sample was consisted of 30 patients (15 boys, 15 girls) whose mean age was $11.76 \pm 0.69$ years at the beginning of treatment and $14.17 \pm 0.95$ years at the end of treatment. The average treatment time was $2.33 \pm 0.66$ years. Each patient presented with remarkable upper arch constriction and narrow inter-canine width causing retro-position of the mandible and convex facial profile due to chin recession. Excessive overjet and crowding could be corrected without extraction by conventional arch expansion and full time class II traction with a force of 4.5-6.5 ounces per side.

The success of the treatment was determined from Class I molar and canine relationships with overjet 2-3 $\mathrm{mm}$, overbite not exceed $1 / 3$ of the lower incisor crown height and acceptable facial profile.

\section{Cephalometric analysis}

Cervical vertebral maturation stage (CVMS) recommended by Baccetti, et al. [16] was assessed. Cephalometric tracing on an acetate paper and measurement were performed by the first author. Dento-skeleton, pharyngeal airway and related structures including soft palate, tongue and hyoid bone before and after treatments were evaluated by means of linear and angular measurements (Figure 1).

\section{Method error of the study}

$\mathrm{T} 1$ and $\mathrm{T} 2$ radiographs of 10 patients were randomly selected for repeated tracing and measurement after an interval of 6 weeks. The first and second measurements were compared using the intra class correlation coefficient (ICC) to evaluate test-retest, intra-rater re- 


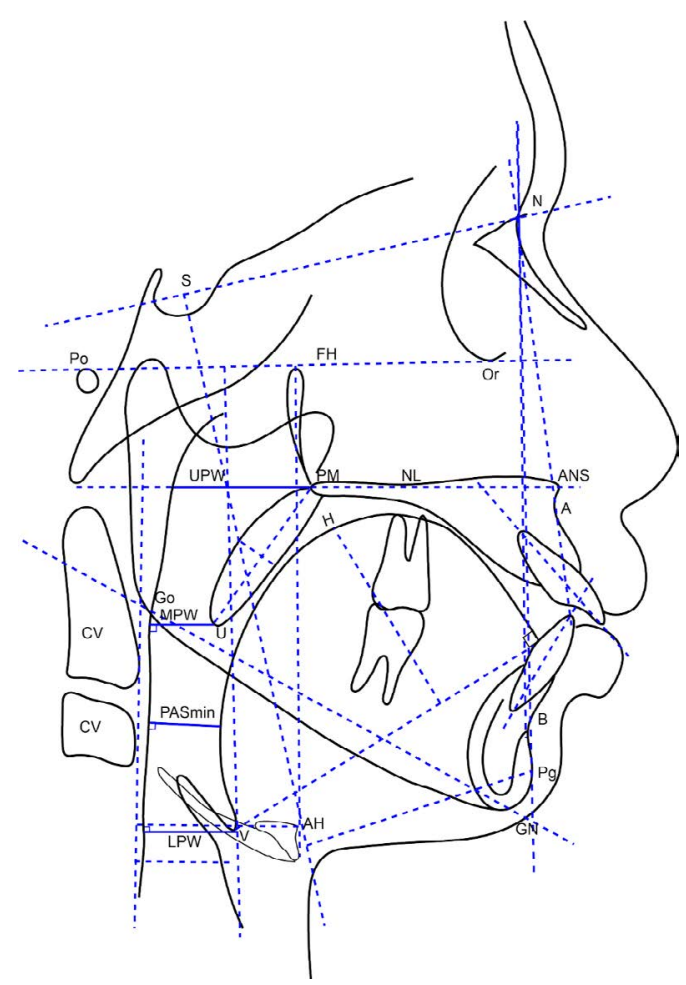

Figure 1: Cephalometric landmarks and measurements of dentoskeletal, pharyngeal airway and related structures.

\begin{tabular}{|c|c|}
\hline Landmarks and reference lines & Definition \\
\hline $\mathrm{AH}$ & $\begin{array}{l}\text { Anterior hyoid, the most anterior and superior point on the body of the hyoid bone, } \\
\text { representing the inferior part of the tongue }\end{array}$ \\
\hline CV & $\begin{array}{l}\text { Cervical vertebrae, the line overlying the anterior surface of the } 2^{\text {nd }} \text { and } 3^{\text {rd }} \text { cervical } \\
\text { vertebrae was used }\end{array}$ \\
\hline $\mathrm{H}$ & $\begin{array}{l}\text { Superior part of the tongue, the most superior point of the tongue in relation to the } \\
\text { line from } V \text { to } T\end{array}$ \\
\hline LPW & $\begin{array}{l}\text { Lower pharyngeal wall, intersection of the perpendicular line from } \mathrm{V} \text { to the posterior } \\
\text { pharyngeal wall }\end{array}$ \\
\hline MPW & $\begin{array}{l}\text { Middle pharyngeal wall, intersection of the perpendicular line from } U \text { to the posterior } \\
\text { pharyngeal wall }\end{array}$ \\
\hline $\mathrm{T}$ & The tip of the tongue \\
\hline$U$ & Uvula, the tip of the uvula \\
\hline UPW & $\begin{array}{l}\text { Upper pharyngeal wall, intersection of the line from the posterior nasal spine to the } \\
\text { posterior pharyngeal wall on the line PM-Ba }\end{array}$ \\
\hline V & Vallecula, the intersection of the epiglottis and the base of the tongue \\
\hline Y axis & Line perpendicular to SN plane through sella \\
\hline \multicolumn{2}{|l|}{ Measurements } \\
\hline Pharyngeal airway & Definition \\
\hline PM-UPW & Depth of nasopharyngeal airway space from PM to UPW \\
\hline U-MPW & Depth of oropharyngeal airway space from U to MPW \\
\hline PASmin & $\begin{array}{l}\text { Depth of the narrowest sagittal airway space; The shortest distance between the } \\
\text { base of the tongue and the posterior pharyngeal wall, }\end{array}$ \\
\hline V-LPW & Depth of hypopharyngeal airway space from $V$ to LPW \\
\hline \multicolumn{2}{|l|}{ Soft palate } \\
\hline NL/PM-U & Inclination of the long axis of the soft palate relative to the nasal line \\
\hline PM-U & Length of soft palate, distance from PM to $U$ \\
\hline SPT & $\begin{array}{l}\text { Soft palate thickness, represents the maximal thickness of soft palate measured } \\
\text { perpendicular to PM-U line }\end{array}$ \\
\hline \multicolumn{2}{|r|}{ 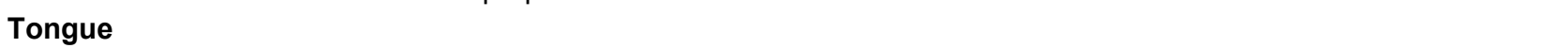 } \\
\hline H-VT & Tongue height, measured as perpendicular distance from $\mathrm{H}$ to VT line \\
\hline VT & Length of tongue, measured as distance from $\mathrm{V}$ to $\mathrm{T}$ \\
\hline $\mathrm{V}-\mathrm{CV}$ & Position of vallecula in horizontal plane, a line from $\mathrm{V}$ to $\mathrm{CV}$ and parallel to $\mathrm{FH}$ \\
\hline $\mathrm{V}-\mathrm{FH}$ & Position of vallecula in vertical plane, a perpendicular line from $\mathrm{V}$ to $\mathrm{FH}$ \\
\hline \multicolumn{2}{|r|}{ 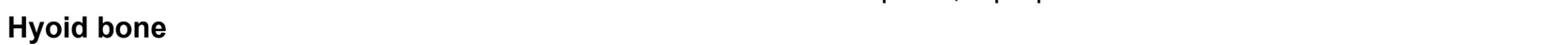 } \\
\hline $\mathrm{AH}-\mathrm{CV}$ & Position of hyoid bone in horizontal plane, from $\mathrm{AH}$ to $\mathrm{CV}$ and parallel to $\mathrm{FH}$ \\
\hline $\mathrm{AH}-\mathrm{FH}$ & Position of hyoid bone in vertical plane, from $\mathrm{AH}$ perpendicular to $\mathrm{FH}$ \\
\hline
\end{tabular}


Table 1: Cervical vertebral maturation stages (CVMS) of the extraction group and the non-extraction group.

\begin{tabular}{|c|c|c|c|c|c|c|c|c|}
\hline \multirow[t]{3}{*}{ CVMS } & \multicolumn{4}{|c|}{ Pre-treatment } & \multicolumn{4}{|c|}{ Post-treatment } \\
\hline & \multicolumn{2}{|c|}{ Extraction group } & \multicolumn{2}{|c|}{ Non-extraction group } & \multicolumn{2}{|c|}{ Extraction group } & \multicolumn{2}{|c|}{ Non-extraction group } \\
\hline & Frequency & Percent & Frequency & Percent & Frequency & Percent & Frequency & Percent \\
\hline 1 & - & - & 2 & 6.7 & - & - & - & - \\
\hline 2 & 14 & 46.7 & 4 & 13.3 & - & - & - & - \\
\hline 3 & 5 & 16.7 & 13 & 43.3 & 3 & 10 & 3 & 10 \\
\hline 4 & 10 & 33.3 & 11 & 36.7 & 15 & 50 & 3 & 10 \\
\hline 5 & 1 & 3.3 & - & - & 12 & 40 & 24 & 80 \\
\hline Total & 30 & 100 & 30 & 100 & 30 & 100 & 30 & 100 \\
\hline
\end{tabular}

Table 2: Pretreatment characteristics of the extraction group and the non-extraction group.

\begin{tabular}{|c|c|c|c|}
\hline Measurements & $\begin{array}{l}\text { Extraction group } \\
(n=30) \\
\text { Mean } \pm \text { SD }\end{array}$ & $\begin{array}{l}\text { Non-extraction group } \\
(\mathrm{n}=30) \\
\text { Mean } \pm \mathrm{SD}\end{array}$ & $\begin{array}{l}\text { Significant difference between } \\
\text { extraction and non-extraction } \\
\text { groups } \\
\text { P Value }\end{array}$ \\
\hline \multicolumn{4}{|l|}{ Skeletal } \\
\hline SNA (deg) & $84.0 \pm 3.6$ & $83.9 \pm 2.9$ & 0.889 \\
\hline SNB (deg) & $79.6 \pm 3.4$ & $77.7 \pm 3.0$ & $0.02^{*}$ \\
\hline ANB (deg) & $4.5 \pm 2.2$ & $6.3 \pm 1.7$ & $0.001^{* *}$ \\
\hline SN-MP (deg) & $32.7 \pm 4.6$ & $32.3 \pm 6.1$ & 0.758 \\
\hline SNPog (deg) & $78.7 \pm 3.3$ & $77.9 \pm 3.6$ & 0.362 \\
\hline Pog to $Y$ axis $(\mathrm{mm})$ & $47.9 \pm 9.5$ & $44.5 \pm 8.1$ & 0.14 \\
\hline \multicolumn{4}{|l|}{ Dental } \\
\hline U1-NA (deg) & $33.0 \pm 6.5$ & $27.3 \pm 7.9$ & $0.003^{* *}$ \\
\hline U1-NA (mm) & $9.2 \pm 2.3$ & $5.9 \pm 2.6$ & $0.000^{* *}$ \\
\hline L1-NB (deg) & $33.6 \pm 5.0$ & $30.5 \pm 4.9$ & $0.019^{*}$ \\
\hline L1-NB (mm) & $8.6 \pm 2.4$ & $7.5 \pm 1.8$ & $0.041^{*}$ \\
\hline \multicolumn{4}{|l|}{ Pharyngeal airway } \\
\hline PM-UPW (mm) & $19.2 \pm 4.7$ & $17.5 \pm 4.7$ & 0.172 \\
\hline U-MPW (mm) & $10.7 \pm 2.2$ & $8.5 \pm 2.6$ & $0.001^{* *}$ \\
\hline PASmin (mm) & $11.6 \pm 3.5$ & $8.9 \pm 2.2$ & $0.001^{* *}$ \\
\hline V-LPW (mm) & $15.9 \pm 2.4$ & $14.5 \pm 2.8$ & $0.046^{*}$ \\
\hline \multicolumn{4}{|l|}{ Soft palate } \\
\hline NL/PM-U (deg) & $131.9 \pm 6.1$ & $132.1 \pm 7.0$ & 0.891 \\
\hline $\mathrm{PM}-\mathrm{U}(\mathrm{mm})$ & $32.0 \pm 3.0$ & $34.0 \pm 3.8$ & $0.029^{*}$ \\
\hline SP-T (mm) & $8.8 \pm 1.2$ & $9.4 \pm 1.5$ & 0.130 \\
\hline \multicolumn{4}{|l|}{ Tongue position } \\
\hline H-VT (mm) & $34.1 \pm 3.4$ & $34.7 \pm 3.7$ & 0.526 \\
\hline VT (mm) & $70.3 \pm 5.9$ & $69.0 \pm 6.1$ & 0.401 \\
\hline $\mathrm{V}-\mathrm{CV}(\mathrm{mm})$ & $19.4 \pm 2.5$ & $17.6 \pm 2.7$ & $0.01^{*}$ \\
\hline $\mathrm{V}-\mathrm{FH}(\mathrm{mm})$ & $78.1 \pm 6.2$ & $80.9 \pm 8.3$ & 0.148 \\
\hline \multicolumn{4}{|l|}{ Hyoid position } \\
\hline $\mathrm{AH}-\mathrm{CV}(\mathrm{mm})$ & $31.6 \pm 2.6$ & $30.7 \pm 3.1$ & 0.251 \\
\hline $\mathrm{AH}-\mathrm{FH}(\mathrm{mm})$ & $80.8 \pm 6.6$ & $83.2 \pm 7.5$ & 0.187 \\
\hline
\end{tabular}

${ }^{*} \mathrm{P} \leq 0.05 ;{ }^{* *} \mathrm{P} \leq 0.01$.

liability. ICC estimates using 2-way mixed-effects model, absolute agreement type and their 95\% confident intervals was calculated using SPSS statistical package. An ICC estimate is 0.91-0.98 regarding as "excellent".

\section{Statistical analysis}

The statistical analysis was calculated using SPSS17.0 (SPSS Inc, Chicago). Kolmogorov-Smirnov test was used to check for normal distribution of all variables. The intra 
group and intergroup comparisons were performed by using paired samples $T$ test and independent samples $T$ test, respectively. Significant correlations of pharyngeal airway changes and dento-skeletal changes were investigated by Pearson's correlation coefficient. The $p \leq 0.05$ was considered statistically significant.

\section{Results}

Skeletal development evaluated from cervical vertebral maturation stages (Table 1 ) indicated that before treatment, the extraction group presented lower level of maturation than those of the non-extraction group.

There were some significant differences of pretreatment characteristics between the two groups (Table 2). The extraction patients presented less retrusive mandible but more protrusive incisors corresponding with wider oropharyngeal airway (U-MPW, PASmin) and hy- popharyngeal airway (V-LPW), shorter soft palate length $(\mathrm{PM}-\mathrm{U})$ and more anterior position of the tongue (V-CV).

After treatment (Table 3), both treatment mechanics produced significant backward rotation of the mandible (SN-MP) and retroclination of the upper incisors (U1-NA). Significant wider of pharyngeal space at the nasopharynx (PM-UPW) and hypopharynx (V-LPW) could be found in the non-extraction group corresponding with increased soft palate length (PM-U) and thickness (SP-T). Positions of the tongue and hyoid bone changed significantly in both groups.

Comparison of treatment changes between the two groups (Table 4) indicated that forward movement of the bony chin (SNPog) and retroclination of the incisors were significantly greater in the extraction group. Forward displacement of the bony chin (SNPog, Pog to $Y$ axis) had significant correlations $(p<0.05)$

Table 3: Treatment effects of the extraction group and the non-extraction group.

\begin{tabular}{|c|c|c|c|c|c|c|}
\hline \multirow[t]{2}{*}{ Measurements } & \multicolumn{3}{|c|}{ Extraction group $(n=30)$} & \multicolumn{3}{|c|}{ Non-extraction group $(n=30)$} \\
\hline & $\begin{array}{l}\text { Pre-treatment } \\
\text { (mean } \pm \text { SD) }\end{array}$ & $\begin{array}{l}\text { Post-treatment } \\
\text { (mean } \pm \text { SD) }\end{array}$ & $\mathbf{P}$ & $\begin{array}{l}\text { Pre-treatment } \\
\text { (mean } \pm \text { SD) }\end{array}$ & $\begin{array}{l}\text { Post-treatment } \\
\text { mean } \pm \text { SD) }\end{array}$ & $\mathbf{P}$ \\
\hline \multicolumn{7}{|l|}{ Skeletal } \\
\hline SNA (deg) & $84.0 \pm 3.6$ & $83.8 \pm 3.3$ & 0.275 & $83.9 \pm 2.9$ & $83.0 \pm 2.8$ & $0.012^{*}$ \\
\hline SNB (deg) & $79.6 \pm 3.4$ & $79.7 \pm 3.5$ & 0.924 & $77.7 \pm 3.0$ & $77.6 \pm 3.2$ & 0.799 \\
\hline ANB (deg) & $4.5 \pm 2.2$ & $4.1 \pm 2.4$ & 0.073 & $6.3 \pm 1.7$ & $5.4 \pm 2.0$ & $0.001^{* *}$ \\
\hline SN-MP (deg) & $32.7 \pm 4.6$ & $33.4 \pm 4.8$ & $0.003^{* *}$ & $32.3 \pm 6.1$ & $33.3 \pm 6.7$ & $0.002^{* *}$ \\
\hline SNPog (deg) & $78.7 \pm 3.3$ & $79.6 \pm 3.4$ & $0.000^{* *}$ & $77.9 \pm 3.6$ & $78.1 \pm 3.7$ & 0.539 \\
\hline Pog to $Y$ axis (mm) & $47.9 \pm 9.5$ & $49.9 \pm 10.5$ & $0.000^{* *}$ & $44.5 \pm 8.1$ & $45.3 \pm 9.1$ & 0.210 \\
\hline \multicolumn{7}{|l|}{ Dental } \\
\hline U1-NA (deg) & $33.0 \pm 6.5$ & $17.5 \pm 6.4$ & $0.000^{* *}$ & $27.3 \pm 7.9$ & $22.3 \pm 5.6$ & $0.000^{* *}$ \\
\hline U1-NA (mm) & $9.2 \pm 2.3$ & $3.4 \pm 2.1$ & $0.000^{\star *}$ & $5.9 \pm 2.6$ & $4.7 \pm 2.3$ & $0.004^{* *}$ \\
\hline L1-NB (deg) & $33.6 \pm 5.0$ & $26.4 \pm 8.4$ & $0.000^{* *}$ & $30.5 \pm 4.9$ & $40.1 \pm 6.4$ & $0.000^{* *}$ \\
\hline L1-NB (mm) & $8.6 \pm 2.4$ & $6.1 \pm 2.8$ & $0.000^{* *}$ & $7.5 \pm 1.8$ & $10.0 \pm 2.3$ & $0.000^{* *}$ \\
\hline \multicolumn{7}{|l|}{ Pharyngeal airway } \\
\hline PM-UPW (mm) & $19.2 \pm 4.7$ & $19.6 \pm 4.3$ & 0.068 & $17.5 \pm 4.7$ & $18.6 \pm 4.7$ & $0.012^{*}$ \\
\hline U-MPW (mm) & $10.7 \pm 2.2$ & $10.5 \pm 2.3$ & 0.525 & $8.5 \pm 2.6$ & $9.2 \pm 2.4$ & 0.079 \\
\hline PASmin (mm) & $11.6 \pm 3.5$ & $10.8 \pm 2.8$ & 0.141 & $8.9 \pm 2.2$ & $8.7 \pm 2.1$ & 0.768 \\
\hline V-LPW (mm) & $15.9 \pm 2.4$ & $16.7 \pm 2.5$ & 0.103 & $14.5 \pm 2.8$ & $15.9 \pm 2.6$ & $0.032^{*}$ \\
\hline \multicolumn{7}{|l|}{ Soft palate } \\
\hline NL/PM-U (deg) & $131.9 \pm 6.1$ & $131.5 \pm 5.9$ & 0.667 & $132.1 \pm 7.0$ & $130.8 \pm 6.2$ & 0.070 \\
\hline PM-U (mm) & $32.0 \pm 3.0$ & $32.3 \pm 2.8$ & 0.084 & $34.0 \pm 3.8$ & $34.6 \pm 3.8$ & $0.025^{*}$ \\
\hline SP-T (mm) & $8.8 \pm 1.2$ & $8.9 \pm 1.2$ & 0.668 & $9.4 \pm 1.5$ & $9.7 \pm 1.7$ & $0.017^{*}$ \\
\hline \multicolumn{7}{|l|}{ Tongue position } \\
\hline $\mathrm{H}-\mathrm{VT}(\mathrm{mm})$ & $34.1 \pm 3.4$ & $35.7 \pm 3.1$ & $0.004^{* *}$ & $34.7 \pm 3.7$ & $37.4 \pm 3.0$ & $0.002^{* *}$ \\
\hline VT (mm) & $70.3 \pm 5.9$ & $70.8 \pm 6.2$ & 0.592 & $69.0 \pm 6.1$ & $72.7 \pm 6.1$ & $0.001^{* *}$ \\
\hline $\mathrm{V}-\mathrm{CV}(\mathrm{mm})$ & $19.4 \pm 2.5$ & $19.9 \pm 2.7$ & 0.174 & $17.6 \pm 2.7$ & $19.4 \pm 2.5$ & $0.007^{* *}$ \\
\hline $\mathrm{V}-\mathrm{FH}(\mathrm{mm})$ & $78.1 \pm 6.2$ & $86.3 \pm 7.4$ & $0.000^{* *}$ & $80.9 \pm 8.3$ & $87.8 \pm 10.6$ & $0.000^{* *}$ \\
\hline \multicolumn{7}{|l|}{ Hyoid position } \\
\hline $\mathrm{AH}-\mathrm{CV}(\mathrm{mm})$ & $31.6 \pm 2.6$ & $33.4 \pm 3.8$ & $0.001^{\star \star}$ & $30.7 \pm 3.1$ & $32.0 \pm 2.9$ & $0.007^{* *}$ \\
\hline $\mathrm{AH}-\mathrm{FH}(\mathrm{mm})$ & $80.8 \pm 6.6$ & $88.0 \pm 8.1$ & $0.000^{* *}$ & $83.2 \pm 7.5$ & $89.4 \pm 11.0$ & $0.000^{* *}$ \\
\hline
\end{tabular}

${ }^{*} \mathrm{P} \leq 0.05^{* *} \mathrm{P} \leq 0.01$ 
Table 4: Comparison of treatment changes between the extraction group and the non-extraction group.

\begin{tabular}{|c|c|c|c|}
\hline Measurements & $\begin{array}{l}\text { Extraction group } \\
(\mathrm{n}=30) \\
(\text { mean } \pm \mathrm{SD})\end{array}$ & $\begin{array}{l}\text { Non-extraction group } \\
(\mathrm{n}=30) \\
\text { (mean } \pm \mathrm{SD})\end{array}$ & Comparisons P Value \\
\hline \multicolumn{4}{|l|}{ Skeletal } \\
\hline SNA (deg) & $-0.3 \pm 1.4$ & $-0.9 \pm 1.9$ & 0.154 \\
\hline SNB (deg) & $0.1 \pm 1.3$ & $-0.1 \pm 1.4$ & 0.667 \\
\hline ANB (deg) & $-0.4 \pm 1.3$ & $-0.9 \pm 1.3$ & 0.222 \\
\hline SN-MP (deg) & $0.7 \pm 1.2$ & $1.0 \pm 1.6$ & 0.369 \\
\hline SNPog (deg) & $0.9 \pm 1.2$ & $0.2 \pm 1.5$ & $0.034^{*}$ \\
\hline Pog to $Y$ axis (mm) & $2.1 \pm 2.7$ & $0.8 \pm 3.4$ & 0.125 \\
\hline \multicolumn{4}{|l|}{ Dental } \\
\hline U1-NA (deg) & $-15.5 \pm 6.5$ & $-5.0 \pm 5.8$ & $0.000^{* *}$ \\
\hline U1-NA (mm) & $-5.8 \pm 2.2$ & $-1.3 \pm 2.2$ & $0.000^{* *}$ \\
\hline L1-NB (deg) & $-7.2 \pm 8.6$ & $9.6 \pm 7.0$ & $0.000^{* *}$ \\
\hline L1-NB (mm) & $-2.5 \pm 2.8$ & $2.5 \pm 1.8$ & $0.000^{* *}$ \\
\hline \multicolumn{4}{|l|}{ Pharyngeal airway } \\
\hline PM-UPW (mm) & $0.4 \pm 1.2$ & $1.1 \pm 2.3$ & 0.132 \\
\hline U-MPW (mm) & $-0.2 \pm 1.9$ & $0.7 \pm 2.2$ & 0.094 \\
\hline PASmin (mm) & $-0.8 \pm 2.7$ & $-0.1 \pm 2.5$ & 0.361 \\
\hline V-LPW (mm) & $0.8 \pm 2.2$ & $1.4 \pm 3.4$ & 0.393 \\
\hline \multicolumn{4}{|l|}{ Soft palate } \\
\hline NL/PM-U (deg) & $-0.3 \pm 3.2$ & $-1.3 \pm 3.7$ & 0.288 \\
\hline PM-U (mm) & $0.3 \pm 1.2$ & $0.6 \pm 1.4$ & 0.406 \\
\hline SP-T (mm) & $0.1 \pm 0.6$ & $0.4 \pm 0.8$ & 0.066 \\
\hline \multicolumn{4}{|l|}{ Tongue position } \\
\hline H-VT (mm) & $1.6 \pm 2.7$ & $2.7 \pm 4.2$ & 0.223 \\
\hline VT (mm) & $0.6 \pm 4.0$ & $3.8 \pm 5.7$ & $0.015^{\star}$ \\
\hline $\mathrm{V}-\mathrm{CV}(\mathrm{mm})$ & $0.5 \pm 1.9$ & $1.7 \pm 3.3$ & 0.085 \\
\hline $\mathrm{V}-\mathrm{FH}(\mathrm{mm})$ & $8.2 \pm 4.5$ & $6.9 \pm 7.0$ & 0.397 \\
\hline \multicolumn{4}{|l|}{ Hyoid position } \\
\hline $\mathrm{AH}-\mathrm{CV}(\mathrm{mm})$ & $1.9 \pm 2.9$ & $1.3 \pm 2.5$ & 0.448 \\
\hline $\mathrm{AH}-\mathrm{FH}(\mathrm{mm})$ & $7.3 \pm 5.1$ & $6.2 \pm 7.1$ & 0.493 \\
\hline
\end{tabular}

${ }^{*} \mathrm{P} \leq 0.05^{* *} \mathrm{P} \leq 0.01$.

Table 5: Significant correlations between changes of pharyngeal airway, tongue, hyoid bone and mandibular position.

\begin{tabular}{|l|l|l|l|}
\hline \multicolumn{2}{|l|}{ Variables } & \multicolumn{1}{l|}{$\begin{array}{l}\text { Diff } \\
\text { SNPog }\end{array}$} & $\begin{array}{l}\text { Diff } \\
\text { Pog to Y axis }\end{array}$ \\
\hline Pharyngeal airway & Pearson Correlation & $0.374^{* *}$ & $0.389^{* *}$ \\
\hline Diff V-LPW & \multicolumn{3}{|l|}{} \\
\hline Tongue position & Pearson Correlation & $0.340^{* *}$ & $0.318^{*}$ \\
\hline Diff V-CV & Pearson Correlation & $0.475^{* *}$ & $0.396^{* *}$ \\
\hline Diff V-FH & & & $0.365^{* *}$ \\
\hline Hyoid bone & Pearson Correlation & $0.426^{* *}$ & $0.318^{*}$ \\
\hline Diff AH-CV & Pearson Correlation & & \\
\hline Diff AH-FH & & & \\
\hline
\end{tabular}

${ }^{* *}$ Correlation is significant at the 0.01 level (2-tailed); *Correlation is significant at the 0.05 level (2-tailed).

with the increase of hypopharyngeal airway (V-LPW), displacements of the tongue and hyoid bone (Table 5).

\section{Discussion}

The Class II division 1 patients of this study present- 
ed skeletal Class II malocclusion with retrusive mandible corresponding with the previous studies $[17,18]$. The extraction or non-extraction treatment for Class II malocclusion was depended on the pretreatment dento-skeletal characteristics. The non-extraction group exhibited more severity of mandibular retrusion, oropharyngeal airway (U-MPW, PASmin) and hypopharyngeal airway (V-LPW) but less incisal proclination (Table 1). According to these features and characteristics, the extraction was avoided. Compromised treatment with arch expansion and Class II traction mechanics was prescribed to obtain acceptable occlusion and facial profile. In the extraction group, both upper and lower incisors exhibited more proclination at the beginning of treatment. Therefore, extraction of four bicuspids was prescribed to obtain adequate space for incisal retraction. The significant differences of mandibular position (SNB, ANB) between the extraction and the non-extraction groups before treatment (Table 2) implied the relation between pharyngeal airway space and the mandibular position. The more severity of mandibular retrusion, the more severity of pharyngeal airway space was manifested. These findings were consistent with the previous study [5]. Facial growth and development should play important role on response of the treatment since skeletal development considered from the CVMS of most subjects have not reached the peak of pubertal growth spurt at the beginning of the treatment (Table 1).

The result indicated that extraction of four bicuspids in growing patients did not produce significant unfavorable effect on the pharyngeal space although the incisors were largely retracted because the mandible still rotated backward (SN-MP) and the bony chin moved forward significantly (SNPog, Pog to $Y$ axis) (Table 3). Actually, reduction of retropalatal (U-MPW) and retroglossal (PASmin) oropharyngeal airway was found in the extraction group but failed to reach statistically significant $(p>0.05)$. The tongue position seemed to be stable (V-CV) when the mandible moved forward. The findings did not support previous suggestion [19] that distal movement of the anterior boundary of oral cavity from large incisal retraction could affect positions of the tongue and soft palate leading to narrowing of the upper airway. Rapid growth of the upper airway [20] during the period of study seemed to mask the effect of incisal retraction.

The non-extraction group presented higher level of maturation than the extraction group (Table 1) indicating less potential of treatment response. The results indicated unsuccessful anterior repositioning of the mandible by Class II elastic traction but only rotated backward. The normal overjet was obtained by significant proclination of the lower incisors, and retroclination of the upper incisors. The nasopharyngeal airway (PM-UPW) and hypopharyngeal airway (V-LPW) increased significantly. This was consistent with the previ- ous study [14] that hypopharyngeal airway and tongue length increased in the Class II traction group. Significant forward position of the tongue was found in the non-extraction group. Alteration of the tongue position should be tongue adaptation to proclination of the lower incisors [21,22]. The nasopharyngeal airway improvement may associate with the reduction of adenoid size. The adenoid reaches its peak size around 12-years-old, and then decreases starting from 12-years-old to reach their adult shape [23]. The increase in length and thickness of the soft palate due to growth, corresponding with the previous finding [24], should play important role for insignificant increase of the oropharyngeal airway at the level of soft palate (U-MPW).

Tongue position considered from root of the tongue related to the Frankfort horizontal plane (V-FH) increased significantly in all groups indicating that it moved downward to compensate the increase in bulk and to maintain function during growth [25]. Both treatment modalities produced significant downward $(\mathrm{AH}-$ $\mathrm{FH}$ ) and forward (AH-CV) displacements of the hyoid bone. The result corresponded with the previous studies $[14,26,27]$ that during puberty, forward movement of the hyoid bone was carried by the chin, and downward movement was closely paralleled with growth of the vertebrae until adulthood.

The significant correlation $(p<0.05)$ between changes of hypopharyngeal airway, positions of the mandible, tongue and hyoid bone (Table 5) supported the previous findings that the hypopharyngeal airway increased after displaced the prolapsed tongue forward [28] and decreased following mandibular setback surgery [29].

Lateral cephalometric measurements of the pharyngeal airway space, a two-dimensional analysis, have been proved to be reliable in diagnosis of pharyngeal volumes [4,30-34]. Martin, et al. [35] evaluated linear and area measurements in two-dimensional views from specific airway regions of interest and compared these to the correspondent volume in CBCT exams. The result showed that the highest positive correlations in the nasopharynx and oropharynx sagittal areas and the most constricted area in the oropharynx. Airway sagittal areas, as well as the most constricted axial area in oropharynx remains a useful guide to correlate with airway volume in two-dimensional images. Therefore, lateral cephalometry can be a good method of reflecting the changes if the standard of taking and measurement are well performed.

\section{Conclusions}

Treatment of Class II division malocclusion in growing patients with four premolar extraction tended to decrease pharyngeal airway space but failed to reach statistical significance. Meanwhile, the hypopharyngeal airway increased significantly after the non-extraction treatment with Class II traction. Alteration of mandib- 
ular position correlated with changes of the hypopharyngeal airway dimension, tongue and hyoid positions.

\section{Author's Contributions}

PS contributed to the literature review, data acquisition, data analysis, data interpretation, and manuscript preparation. SV contributed to the treatment of the patients and data collection, design of the study, data interpretation, and manuscript editing. Both authors read and approved the final manuscript.

\section{Acknowledgement}

This research did not receive any specific grant from funding agencies in the public, commercial, or not-forprofit sectors.

\section{Conflict of Interest}

The authors declare no conflicts of interest to disclose.

\section{References}

1. McNamara JA (1981) Influence of respiratory pattern on craniofacial growth. Angle Orthod 51: 269-300.

2. Moss-Salentijn L (1997) Melvin L. Moss and the functional matrix. J Dent Res 76: 1814-1817.

3. Gupta RK, Chandra A, Verm AK, Kumar S (2010) Obstructive sleep apnoea: A clinical review. J Assoc Physicians India 58: 438-441.

4. deBerry-Borowiecki B, Kukwa A, Blanks RH (1988) Cephalometric analysis for diagnosis and treatment of obstructive sleep apnea. Laryngoscope 98: 226-234.

5. Muto T, Yamazaki A, Takeda S (2008) A cephalometric evaluation of the pharyngeal airway space in patients with mandibular retrognathia and prognathia, and normal subjects. Int J Oral Maxillofac Surg 37: 228-231.

6. Mergen DC, Jacobs RM (1970) The size of nasopharynx associated with normal occlusion and class ii malocclusion. Angle Orthod 40: 342-346.

7. Kerr WJ (1985) The nasopharynx, face height, and overbite. Angle Orthod 55: 31-36.

8. El H, Palomo JM (2011) Airway volume for different dentofacial skeletal patterns. Am J Orthod Dentofacial Orthop 139: 511-521.

9. Jacob HB, Buschang PH, dos Santos-Pinto A (2013) Class ii malocclusion treatment using high-pull headgear with a splint: A systematic review. Dental Press J Orthod 18: 21.

10. Ghafari J, Shofer FS, Jacobsson-Hunt U, Markowitz DL, Laster LL (1998) Headgear versus function regulator in the early treatment of class ii, division 1 malocclusion: $A$ randomized clinical trial. Am J Orthod Dentofacial Orthop 113: 51-61.

11. Pangrazio-Kulbersh V, Berger JL, Kaczynski R, Shunock M (2001) Stability of skeletal class ii correction with 2 surgical techniques: The sagittal split ramus osteotomy and the total mandibular subapical alveolar osteotomy. Am J Orthod Dentofacial Orthop 120: 134-143.

12. Maetevorakul S, Viteporn S (2015) Soft tissue profile changes following treatment of class ii division 1 malocclusion with different orthodontic modalities. CU Dent J 38: 53-66.
13. Maetevorakul S, Viteporn S (2016) Factors influencing soft tissue profile changes following orthodontic treatment in patients with class ii division 1 malocclusion. Prog Orthod 17: 13.

14. Zheng BW, Jiang ZX, Liu F, An N, Zheng Y, et al. (2015) Effect of headgear and class ii traction on upper airway dimensions and hyoid bone position in non-extraction patients with class ii division 1 malocclusion. J Hard Tissue Biology 24: 1-6.

15. Aksu M, Gorucu-Coskuner H, Taner T (2017) Assessment of upper airway size after orthopedic treatment for maxillary protrusion or mandibular retrusion. Am J Orthod Dentofacial Orthop 152: 364-370.

16. Baccetti T, Franchi L, McNamara JA (2005) The cervical vertebral maturation (cvm) method for the assessment of optimal treatment timing in dentofacial orthopedics. Seminars in Orthodontics 11: 119-129.

17. McNamara JA Jr (1981) Components of class ii malocclusion in children 8-10 years of age. Angle Orthod 51: 177-202.

18. Al-Khateeb EA, Al-Khateeb SN (2009) Anteroposterior and vertical components of class ii division 1 and division 2 malocclusion. Angle Orthod 79: 859-866.

19. Hu Z, Yin X, Liao J, Zhou C, Yang Z, et al. (2015) The effect of teeth extraction for orthodontic treatment on the upper airway: A systematic review. Sleep Breath 19: 441-451.

20. Chiang CC, Jeffres MN, Miller A, Hatcher DC (2012) Threedimensional airway evaluation in 387 subjects from one university orthodontic clinic using cone beam computed tomography. Angle Orthod 82: 985-992.

21. Peat JH (1968) A cephalometric study of tongue position. Am J Orthod 54: 339-351.

22. Ballard CF (1961) Oro-facial behavior. Public Health 76 : 10-18.

23. Scammon R, Harris J, Jackson C, Paterson D (1930) The measurement of the body in childhood. University of Minnesota Press, 173-215.

24. Johnston CD, Richardson A (1999) Cephalometric changes in adult pharyngeal morphology. Eur J Orthod 21: 357-362.

25. Tourne LP (1991) Growth of the pharynx and its physiologic implications. Am J Orthod Dentofacial Orthop 99: 129-139.

26. Tsai HH (2007) Developmental changes of pharyngeal airway structures from young to adult persons. J Clin Pediatr Dent 31: 219-221.

27. King EW (1952) A roentgenographic study of pharyngeal growth. Angle Orthod 22: 23-37.

28. Mann EA, Burnett T, Cornell S, Ludlow CL (2002) The effect of neuromuscular stimulation of the genioglossus on the hypopharyngeal airway. Laryngoscope 112: 351-356.

29. Enacar A, Aksoy AU, Sencift Y, Haydar B, Aras K (1994) Changes in hypopharyngeal airway space and in tongue and hyoid bone positions following the surgical correction of mandibular prognathism. Int $\mathrm{J}$ Adult Orthodon Orthognath Surg 9: 285-290.

30. Riley R, Guilleminault C, Herran J, Powell N (1983) Cephalometric analyses and flow-volume loops in obstructive sleep apnea patients. Sleep 6: 303-311.

31. Mislik B, Hanggi MP, Signorelli L, Peltomaki TA, Patcas R (2014) Pharyngeal airway dimensions: A cephalometric, growth-study-based analysis of physiological variations in children aged 6-17. Eur J Orthod 36: 331-339. 
32. Germec-Cakan D, Taner T, Akan S (2011) Uvuloglossopharyngeal dimensions in non-extraction, extraction with minimum anchorage, and extraction with maximum anchorage. Eur J Orthod 33: 515-520.

33. Wang Q, Jia P, Anderson NK, Wang L, Lin J (2012) Changes of pharyngeal airway size and hyoid bone position following orthodontic treatment of Class I bimaxillary protrusion. Angle Orthod 82: 115-121.
34. Bhatia S, Jayan B, Chopra SS (2016) Effect of retraction of anterior teeth on pharyngeal airway and hyoid bone position in class i bimaxillary dentoalveolar protrusion. Med J Armed Forces India 72: S17-S23.

35. Martins LS, Liedke GS, Heraldo L, da Silveira PF, Arus NA, et al. (2018) Airway volume analysis: Is there a correlation between two and three-dimensions? Eur J Orthod 40: 262267. 